\title{
Recent advances in the treatment of peritoneal metastasis from gastric cancer
}

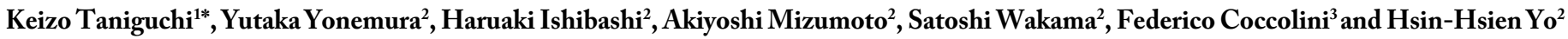 \\ ${ }^{1}$ Department of Surgery, Teikyo University Mizonokuchi Hospital, Kawazsaki, Japan \\ ${ }^{2}$ Peritoneal Surface Malignancy Treatment Center, Kishiwada Tokushukai Hospital and Kusatsu General Hospi-tal, Oosaka, Shiga, Japan \\ ${ }^{3}$ General Surgery Department, Ospedola, Maggiore, Parma, Italy
}

\begin{abstract}
Background: Peritoneal metastasis (PM) from gastric cancer (GC) was once considered a lethal disease. After the late 1990s, the therapeutic goal changed from palliative to curative intent because of a development a comprehensive treatment combining cytoreductive surgery (CRS) and perioperative chemotherapy.

Methods: Recent advances in the treatment of PM from GC reported in 18 studies including 2327 patients were reviewed.

Results: In patients with PM, systemic chemotherapy alone had a limited and non-curative effect. In contrast, radical gastrectomy plus neoadjuvant intraperitoneal/ systemic chemotherapy (NIPS), early postoperative intraperitoneal chemotherapy (EPIC), or postoperative S1 treatment was shown to improve the survival of patients with cytology-positive (Cy1) peritoneal lavage fluid without macroscopic PM (P0) (P0Cy1). After 5 years, 23 among 154 patients were disease free. For the treatment of patients with macroscopic PM (P1), exploratory laparotomy to determine the peritoneal cancer index (PCI) and neoadjuvant laparoscopic hyperthermic intraperitoneal perfusion (LHIPEC) were performed. The combination of NIPS and LHIPEC was effective in patients with P1, but NIPS or LHIPEC alone were ineffective and all patients receiving one or the other died. In contrast, the 5-year survival rate after cytoreductive surgery (CRS)+HIPEC ranged from $6 \%$ to $13 \%$, and 18 among 284 patients were disease free at 5 years.
\end{abstract}

Conclusions: Although CRS and NIPS have an important role in treatment of PM from GC, complete cytoreduction by gastrectomy and peritonectomy after NIPS combined with intraoperative HIPEC, EPIC, and late postoperative chemotherapy may cure the patients with P0Cy1 or P1 disease.

\section{Synopsis}

Recent advances in the treatment of PM from GC were reviewed. Radical gastrectomy plus perioperative chemotherapy improved the survival of patients with intraperitoneal micro metastasis. Complete cytoreduction combined with perioperative chemotherapy may cure the patients with macroscopic PM.

Most frequent cause of gastric cancer (GC) death is peritoneal metastasis (PM), with death occurring in $53-60 \%$ of advanced gastric cancer patients. PM from GC is considered an independent prognostic factor for poor prognosis [1]. Accordingly, PM from GC has been considered a lethal condition. Despite the development of many new systemic chemotherapy, systemic chemotherapy of PM from GC remains poor [2-7]. Recently, intraperitoneal chemotherapy (IPC) was proposed as an effective treatment to improve survival [8]. Yonemura $\mathrm{Y}$, et al. [8] and Glehen $\mathrm{O}$, et al. [9] reported that IPC/hyperthermic intraperitoneal chemoperfusion (HIPEC) combined with cytoreductive surgery (CRS) (but not IPC alone) significantly improved the survival of GC patients with PM. Additionally, some patients were cured by a combination of neoadjuvant IPC, CRS, HIPEC, and postoperative chemotherapy [10]. The present review demonstrates that recent advances in the treatment of PM from GC have significantly improved prognosis.

\section{Limits of systemic chemotherapy for peritoneal metas- tasis from gastric cancer}

Table1 shows the effect of systemic chemotherapy on survival in GC patients with macroscopic PM (P1 group). In patients in P1 group treated with systemic chemotherapy alone, median survival time (MST) ranged from 5.0 to 13.0 months, and the one- ad 5-year survival rates after systemic chemotherapy alone were reported to be 7.7 $13.0 \%$ and $0-3.4 \%$, respectively [2,4-7]. Hong SH reported that overall survival (OS) was associated with the extent of PM [6]. Although a small number of patients survived longer than 5 years after systemic chemotherapy and gastrectomy, all patients died of PC within 8 years after chemotherapy. Accordingly, the effect of systemic chemotherapy on survival improvement is limited, and systemic chemotherapy alone cannot cure patients with PM. The reasons include the existence of the plasma-peritoneal barrier [11] and cancer stem cells [12].

Treatment for intraperitoneal micrometastasis (cytology-positive (Cy1) peritoneal lavage fluid without macroscopic PM (P0); (P0Cyl group) by systemic chemotherapy or IPC

The 5-year survival rate after radical gastrectomy alone in $\mathrm{P} 0 \mathrm{Cy} 1$ patients is reported to be only $2 \%$ [13]. Therefore, P0Cyl patients are considered to have peritoneal metastases, and P0Cyl gastric cancer is classified as stage IV [14]. As shown in Table 1, survival is significantly

Correspondence to: Keizo Taniguchi, Department of Surgery, Teikyo University Mizonokuchi Hospital, Kawasaki, Japan, E-mail: keizotng16@me.com

Received: January 17, 2018; Accepted: February 09, 2018; Published: February 13,2018 
Table 1. Outcome of patients with peritoneal metastasis from gastric cancer treated by systemic chemotherapy alone

\begin{tabular}{|c|c|c|c|c|c|c|c|c|}
\hline Authors & Treatments and tumor status & No. of Patients & MST & Response rate & $\begin{array}{l}1 \text { year } \\
\text { survival rate }\end{array}$ & $\begin{array}{l}5 \text { years } \\
\text { survival rate }\end{array}$ & $\begin{array}{l}\text { No. of disease free } \\
\text { survivors after } 5 \\
\text { years }\end{array}$ & $\begin{array}{l}\text { Side effects } \\
\text { Grade 3,4,5 } \\
\text { (Grade 5) }\end{array}$ \\
\hline \multicolumn{9}{|c|}{ Macroscopic peritoneal metastasis (P1 group) } \\
\hline \multirow[t]{2}{*}{ Nishina T [4] } & 5-FU+(MTX) & 49 & $7.7 \mathrm{~m}$ & Not described & $27.10 \%$ & $0 \%$ & 0 & $0-28.6 \%(0 \%)$ \\
\hline & Paclitaxel & 51 & $7.7 \mathrm{~m}$ & Not described & $31.40 \%$ & $0 \%$ & 0 & $0-17.6 \%(0 \%)$ \\
\hline \multirow[t]{2}{*}{ Koizumi W [2] } & $\mathrm{S} 1+\mathrm{CDDP}$ & $148(51)^{\#}$ & $13.0 \mathrm{~m}$ & $54 \%$ & $54.10 \%$ & NR & 0 & $0-11 \%(0 \%)$ \\
\hline & $\mathrm{S} 1$ & $150(36)^{\#}$ & $11.0 \mathrm{~m}$ & $31.00 \%$ & $46.70 \%$ & NR & 0 & $0-40 \%(0 \%)$ \\
\hline Imamoto H [5] & Paclitaxel & 64 & $5.0 \mathrm{~m}$ & $31.30 \%$ & $20 \%$ & $0 \%$ & 0 & $7.9-22.2 \%(-\%)$ \\
\hline \multirow[t]{5}{*}{ Hong SH [6] } & Various regimens $\$$ & 211 & & & & & & \\
\hline & Measurable disease & 74 & $11.6 \mathrm{~m}$ & Not described & $49.80 \%$ & NR & 0 & - \\
\hline & Non-measurable disease & 137 & $18.0 \mathrm{~m}$ & Not described & $68.40 \%$ & $12 \%$ & 0 & - \\
\hline & Gastrectomy+chemotherapy & 44 & $29.3 \mathrm{~m}$ & Not described & $85.40 \%$ & $7.70 \%$ & 0 & - \\
\hline & chemotherapy alone & 61 & $12.5 \mathrm{~m}$ & not described & $54.30 \%$ & $3.40 \%$ & 0 & - \\
\hline \multirow[t]{2}{*}{ Wilke H [7] } & Ramucirumab & 330 (163)\# & $9.6 \mathrm{~m}$ & $17 \%$ & $42 \%$ & NR & NR & $81 \%(12 \%)$ \\
\hline & Ramucirumab+paclitaxel & 335 (152)\# & $7.4 \mathrm{~m}$ & $28 \%$ & $30 \%$ & NR & NR & $63 \%(16 \%)$ \\
\hline \multicolumn{9}{|c|}{ Cytology-positive peritoneal lavage fluid and without macroscopic peritoneal metastasis (P0Cy1 group) } \\
\hline \multirow{2}{*}{ Yonemura Y [14] } & Gastrectomy+S-1 & 35 & $18.3 \mathrm{~m}$ & & $83 \%$ & $36.80 \%$ & 4 & $0-9 \%(0 \%)$ \\
\hline & Gastrectomy alone & 66 & $8.8 \mathrm{~m}$ & & $37 \%$ & NR & & \\
\hline Kodera Y [15] & Gastrectomy+S-1 & 48 & $23.5 \mathrm{~m}$ & & $78 \%$ & $32 \%$ & 1 & $2-13 \%(0 \%)$ \\
\hline
\end{tabular}

\$: 5-FU/CDDP:155; \#(): Number of patients with peritoneal metastasis; Taxan/CDDP:25, FOLFIRI:12; oral 5-FU: 12, others: 7

better in patients after radical gastrectomy plus postoperative oral S1 treatment than after gastrectomy alone $[13,15,16]$. Furthermore, disease-free survival longer than 5 years has been reported after gastrectomy $[15,16]$. Table 2 shows the outcomes of P0Cyl patients treated with gastrectomy plus IPC. Fujiwara Y [17] and Yonemura Y [18] treated PoCyl patients with radical gastrectomy after neoadjuvant intraperitoneal/systemic chemotherapy (NIPS) using oral S-1+IP docetaxel with or without IP CDDP. After NIPS, positive cytology became negative cytology in $75-78 \%$ of patients $[17,18]$. The 5 -year survival rate after NIPS+gastrectomy was $42 \%$ and 2 patients remained in disease-free 5 years after NIPS [10]. In their P0Cy1 patients, a 3-arm randomized study, Kuramoto, et al. found that patients treated with extensive intraoperative peritoneal lavage (EIPL)+gastrectomy+early postoperative intraperitoneal chemotherapy (EPIC) (2-hour IP administration of CDDP at the time of abdominal closure) survived significantly longer than those treated with gastrectomy+EPIC or gastrectomy alone [19]. In EIPL, the peritoneal cavity is extensively shaken and washed after intraperitoneal injection of $1 \mathrm{~L}$ of saline, and the saline is completely aspirated. This procedure is done 10 times [19]. EIPL removes both peritoneal free cancer cells and those adhering to the peritoneal surface. EIPL+EPIC significantly improves the 5-year survival rate in P0Cy1 patients, because it significantly decreases the number of cancer cells in the peritoneal cavity [19].

Imano, et al. also reported that gastrectomy+EPIC using paclitaxel (PTX) changed positive cytology to negative cytology in 100\% (10/10) of P0Cy1 patients, and that 5-year survival rate was $25 \%$ [20].

These results strongly indicate that postoperative oral S1, NIPS, or EPIC can eradicate intraperitoneal micro-metastasis in $25-44 \%$ of P0Cy1 patients, bringing about cure $[17,18,20,21]$.

\section{Intraperitoneal chemotherapy (IPC) for peritoneal me- tastasis (P1 group)}

Recently, IPC has shown encouraging results for the treatment of PM and has the following advantages: (1) the drugs act directly on not only cancer cells floating in the peritoneal fluid but also metastatic nodules on the peritoneal surface, (2) IPC achieves a significantly higher drug concentration in the peritoneal cavity as compared with systemic chemotherapy (3) The half-life of high molecular weight drugs in the peritoneal cavity is prolonged and systemic toxicity is reduced. However, IPC does not work in patients with peritoneal adhesions. Accordingly, IPC is mainly used preoperatively. Additionally, drug penetration distance from the peritoneal surface is different from drug to drug. The depth of penetration from the peritoneal surface is just several hundred $\mu \mathrm{m}$ for methotrexate, 5FU, paclitaxel, and carboplatinum [22-25]. Accordingly, multiple intraperitoneal administrations of anticancer drugs are necessary to treat big nodules larger than the depth of penetration of each locally applied anticancer drug [25]. Additionally, combining IPC with systemic chemotherapy extends the treatable area of subperitoneal tissue. Systemic chemotherapy can be effective against deep seated tumors that are accessible through subperitoneal arterial capillaries but inaccessible through IPC. This strategy is known as neoadjuvant intraperitoneal/systemic chemotherapy (NIPS).

Taxans are high molecular weight compounds. IP administered taxans are gradually absorbed through lymphatic stomata or omental milky spots and migrate into lymph nodes and thoracic ducts $[25,26]$. In contrast, low molecular weight compounds like mitomycin $\mathrm{C}$ (MMC) or CDDP are rapidly absorbed from peritoneal surface into subperitoneal blood vessels. The area under the curve ratios of the intraabdominal space to the plasma after IP administration of the drugs are about 1000 for paclitaxel (PTX), 207-552 for docetaxel (DTX), 10-24 for MMC, and 12-21 for CDDP [27-30].

To achieve high loco-regional dose intensity in the peritoneal cavity and to reduce systemic toxicities, taxans (PTX and DTX) are the ideal drugs for IPC $[29,31]$. From the phase I studies, the maximum tolerated dose (MTD) and recommended dose (RD) were $90 \mathrm{mg} / \mathrm{m}^{2}$ and $80 \mathrm{mg} / \mathrm{m}^{2}$ for PTX [27], and $50 \mathrm{mg} / \mathrm{m}^{2}$ and $45 \mathrm{~g} / \mathrm{m}^{2}$ for DTX [28]. Table 3 shows the clinical outcomes of NIPS using IP administration of taxans for PM from gastric cancer.

The incidence of Grade 3, 4, or 5 side effects after IPC was lower after IPC with taxans (6.3\% to $18.5 \%)$ [18,32-34], and the incidences are lower than those after systemic chemotherapy ( $0 \%$ to $81 \%$ ) (Tables 1 and 3) [2,4-7]

Histologic and cytologic responses to NIPS were excellent (Table 3). Histologic responses of grade 2 and 3 (viable cancer cells remaining in 
Taniguchi K (2018) Recent advances in the treatment of peritoneal metastasis from gastric cancer

Table 2. Outcome of patients showing cytology-positive peritoneal lavage fluid and no macroscopic peritoneal metastasis (P0Cy1 group) who were treated with IP chemotherapy

\begin{tabular}{|c|c|c|c|c|c|c|c|c|c|}
\hline Authors & Treatments & Patients no. & MST & Response & $\begin{array}{l}\text { 1-year } \\
\text { survival } \\
\text { rate }\end{array}$ & $\begin{array}{l}\text { 5-year } \\
\text { survival } \\
\text { rate }\end{array}$ & $\begin{array}{l}\text { No. of } \\
\text { disease free } \\
\text { survivors } \\
\text { after } 5 \text { years }\end{array}$ & $\begin{array}{l}\text { Side effects } \\
\text { Grade } 3,4,5\end{array}$ & $\begin{array}{l}\text { Postoperative } \\
\text { complication } \\
\text { Grade } 3,4,5\end{array}$ \\
\hline $\begin{array}{l}\text { Fujiwara Y } \\
{[17]}\end{array}$ & $\begin{array}{l}\text { NIPS (S1: Day 1-14 } \\
\text { IP DOC Day1 x2 cycles) } \\
\text { plus gastrectomy }\end{array}$ & 18 & $24.6 \mathrm{~m}$ & $\begin{array}{l}\text { Positive cytology } \\
\text { became negative } \\
14 / 18(78 \%)\end{array}$ & $85 \%$ & NR & NR & $\begin{array}{l}0-6 \% \\
\text { (grade 5=0) }\end{array}$ & $\begin{array}{l}3(19 \%) \\
\text { Grade } 5: 0\end{array}$ \\
\hline $\begin{array}{l}\text { Yonemura Y } \\
{[18]}\end{array}$ & $\begin{array}{l}\text { NIPS (S-1 8: Day 1-14, } \\
\text { IP DOC Day } 1 \text { and Day } 8 \text { x } 3 \\
\text { plus CRS plus HIPEC }\end{array}$ & 20 & $36 \mathrm{~m}$ & $\begin{array}{l}\text { Positive cytology } \\
\text { became negative } \\
15 / 20(75 \%)\end{array}$ & $75 \%$ & $42 \%$ & 2 & $0 \%$ & $0 \%$ \\
\hline $\begin{array}{l}\text { Kuramoto M } \\
{[19]}\end{array}$ & $\begin{array}{l}\text { EIPL }{ }^{\#}+\text { IP CDDP + gastrectomy } \\
\text { IP CDDP+gastrectomy } \\
\text { gastrectomy alone }\end{array}$ & $\begin{array}{l}30 \\
29 \\
29\end{array}$ & $\begin{array}{l}36 \mathrm{~m} \\
16 \mathrm{~m} \\
15 \mathrm{~m}\end{array}$ & & $\begin{array}{l}85 \% \\
62 \% \\
58 \%\end{array}$ & $\begin{array}{l}43.8 \% \\
4.5 \% \\
0 \%\end{array}$ & $\begin{array}{l}8 \\
1 \\
0\end{array}$ & not described & Not described \\
\hline Imano M [20] & $\begin{array}{l}\text { Gastrectomy+ IP PTX } \\
\text { Gastrectomy }\end{array}$ & $\begin{array}{l}10 \\
6\end{array}$ & $\begin{array}{l}38 \mathrm{~m} \\
13 \mathrm{~m}\end{array}$ & $\begin{array}{l}\text { Positive cytology } \\
\text { became negative } \\
10 / 10(100 \%)\end{array}$ & $\begin{array}{l}100 \% \\
63 \%\end{array}$ & $\begin{array}{l}25 \% \\
0 \%\end{array}$ & $\begin{array}{l}2 \\
0\end{array}$ & $\begin{array}{l}0 \% \\
0 \%\end{array}$ & $0 \%$ \\
\hline
\end{tabular}

\#: EIPL: Extensive intreoperative peritoneal lavage

Table 3. Outcomes of gastric cancer patients with macroscopic peritoneal metastasis (P-positive group) after treatment with neoadjuvant intraperitoneal/systemic chemotherapy plus/minus gastrectomy

\begin{tabular}{|c|c|c|c|c|c|c|c|c|c|}
\hline Authors & NIPS and operations & Patients no. & MST & Response & $\begin{array}{l}\text { 1-year } \\
\text { survival rate }\end{array}$ & $\begin{array}{l}\text { 5-year } \\
\text { survival rate }\end{array}$ & $\begin{array}{l}\text { No of disease free } \\
\text { survivors after } 5 \\
\text { years }\end{array}$ & $\begin{array}{l}\text { Side effects } \\
\text { Grade } 3,4,5\end{array}$ & $\begin{array}{l}\text { Postoperative } \\
\text { complication } \\
(\text { Grade } 3,4,5)\end{array}$ \\
\hline Fushida S [28] & S-1 Day1-14 & $27(\mathrm{CRS}=14)$ & $16.2 \mathrm{~m}$ & $\begin{array}{l}\text { Response of } \\
\text { measurable }\end{array}$ & $92.80 \%$ & NR & NR & $7.4 \%-18.5 \%$ & $4(25 \%)$ \\
\hline Phase II & IP DTX (day1, day 15) & & & lesions $14 / 27(52 \%)$ & & & & Grade $5=0$ & Grade $5: 0$ \\
\hline Ishigami H [21] & S-1 Day1-14 & Total number $(\mathrm{N}=100)$ & $20.6 \mathrm{~m}$ & Histologic response & & & & & \\
\hline \multirow[t]{2}{*}{ RCT } & $\begin{array}{l}\text { IP PTX/ IV PTX day } \\
1 \text {, day8 }\end{array}$ & Gastrectomy $(\mathrm{N}=64)$ & $30.50 \%$ & Grade $2,3: 25 \%$ & $73.30 \%$ & $16 \%$ & 4 & & $0 \%$ \\
\hline & & no gastrectomy $(\mathrm{N}=36)$ & $12.10 \%$ & & $56 \%$ & $0 \%$ & 0 & & \\
\hline \multirow[t]{2}{*}{ Ishigami H [21] } & Same as above & CCR-0 $(\mathrm{N}=44)$ & $30 \mathrm{~m}$ & & $81 \%$ & $25 \%$ & 4 & & $3.10 \%$ \\
\hline & & CCR-1 $(\mathrm{N}=20$ & $30 \mathrm{~m}$ & & $100 \%$ & $0 \%$ & 0 & & Grade $5: 0$ \\
\hline \multirow[t]{2}{*}{ Ishigami H [21] } & Same as above & P0Cy1 (N=11) & $36 \mathrm{~m}$ & & $90 \%$ & $50 \%$ & 40 & & \\
\hline & & P2, P3 $(\mathrm{N}=53)$ & $30 \mathrm{~m}$ & & $90 \%$ & $0 \%$ & & & \\
\hline \multirow[t]{3}{*}{$\begin{array}{l}\text { Yonemura Y } \\
{[42]}\end{array}$} & $\begin{array}{l}\text { NIPS (oral S-1: day } \\
1-14\end{array}$ & $\begin{array}{l}\text { NIPS+CRS+HIPEC } \\
(\mathrm{N}=41)\end{array}$ & $20.4 \mathrm{~m}$ & $\begin{array}{l}\text { Positive cytology } \\
\text { (Cy) to }\end{array}$ & $67.40 \%$ & $20 \%$ & 2 & $5 / 79(6.3 \%)$ & Not described \\
\hline & $\begin{array}{l}\text { IP DOC+CDDP Day } \\
\text { 1, Day8) }\end{array}$ & NIPS alone $(\mathrm{N}=38)$ & $10.6 \mathrm{~m}$ & $\begin{array}{l}\text { negative Cy 63\% } \\
(41 / 65)\end{array}$ & $35.90 \%$ & NR & NR & Grade $5=0$ & \\
\hline & & & & $\begin{array}{l}\text { Complete } \\
\text { disappearance } 50 \%\end{array}$ & & & & & \\
\hline
\end{tabular}

CCR-0(complete cytoreduction)

CCR-1 (incomplete cytoreduction)

Table 4. Outcomes of cytoreductive surgery (radical gastrectomy+peritonectomy) and hyperthermic intraperitoneal chemoperfusion (HIPEC) with or without NIPS for removal ofperitoneal metastasis from gastric cancer

\begin{tabular}{|c|c|c|c|c|c|c|c|c|}
\hline Authors & No of patients & Drugs used in HIPEC & MST & $\begin{array}{l}1 \text {-year } \\
\text { survival rate }\end{array}$ & $\begin{array}{l}\text { 5-year } \\
\text { survival } \\
\text { rate }\end{array}$ & $\begin{array}{l}\text { No. of disease free } \\
\text { survivors after } 5 \text { years }\end{array}$ & $\begin{array}{l}\text { Prognostic } \\
\text { factors }\end{array}$ & $\begin{array}{l}\text { Mortality (Grade 5) } \\
\text { morbidity (Grade 3,4) }\end{array}$ \\
\hline Glehen O [36] & 49 & CRS+ HIPEC (MMC+CDDP) & Overall: $9.2 \mathrm{~m}$ & $43 \%$ & $13 \%$ & 5 & CCR- 0 & Grade 5: $6.5 \%$ \\
\hline \multirow{2}{*}{ non-RCT } & CCR-0: $\mathrm{N}=25$ & or LOHP+Irrinotecan) & CCR-0:21.3m & $\begin{array}{l}\text { CCR-0: } \\
61 \%\end{array}$ & CCR-0:23\% & 4 & $\mathrm{PCI}=<12$ & Grade $3,4: 27.8 \%$ \\
\hline & CCR-1: $N=24$ & & CCR-1:6.6m & $\begin{array}{l}\text { CCR- } \\
1: 15.8 \%\end{array}$ & CCR-1: $0 \%$ & 1 & & \\
\hline Hall JJ [37] & 34 & CRS+HIPEC with MMC & $8.0 \mathrm{~m}$ & $41 \%$ & $6 \%$ & 1 & CCR-0 & $\begin{array}{l}\text { Grade } 5: 0 \% \text {, Grade } \\
3,4: 35 \%\end{array}$ \\
\hline non-RCT & 40 & no HIPEC & $7.8 \mathrm{~m}$ & $38 \%$ & $17 \%$ & 4 & & $\begin{array}{l}\text { Grade 5: } 17.5 \% \text {, } \\
\text { Grade 3,4: } 15 \%\end{array}$ \\
\hline Yang XJ [40] & 34 & CRS + HIPEC (CDDP+MMC) & $11.0 \mathrm{~m}$ & $41.20 \%$ & NR & NR & HIPEC, CCR-0 & Grade $34,5: 11.7 \%$ \\
\hline $\mathrm{RCT}$ & 34 & CRS alone & $6.5 \mathrm{~m}$ & $29.40 \%$ & $0 \%$ & 0 & $\begin{array}{l}\text { Systemic chemo. } \\
>=6 \text { cycles }\end{array}$ & Grade $3,4,5: 14.7 \%$ \\
\hline $\begin{array}{l}\text { Yonemura Y } \\
{[10]}\end{array}$ & 201 & NIPS+CRS+HIPEC & $15.5 \mathrm{~m}(\mathrm{CCR}-0)$ & $65.00 \%$ & $15 \%$ & 12 & CCR-0, NIPS & Grade 5: $2 \%$ \\
\hline non RCT & & (DTX+CDDP) & 8.0m (CCR-1) & $38 \%$ & $2 \%$ & 0 & $\mathrm{PCI}=<6$ & Grade 3 or $4: 32 \%$ \\
\hline
\end{tabular}


less than one third of the tumorous area [14]) disappeared completely in $25 \%$ of patients treated with NIPS using S-1+PTX [21]. Macroscopic PM disappeared completely $15(50 \%)$ of 30 patients after NIPS using DTX+CDDP [32,34], and in 52\% of patients after NIPS using S1+DTX (Table 2) [33]. In contrast, response rates were lower after systemic chemotherapy than after IPC (Table 1) [2,5,7].

Negative peritoneal wash cytology at the time of CRS was reported to be a significant favorable prognostic factor [34]. IP port cytology showed a change from positive cytology to negative cytology after IPC in $63-67 \%$ of patients (Table 3 ) $[32,24]$.

Histologic and cytologic effects of NIPS were independent prognostic factors after CRS [21,34]. Accordingly, NIPS is a powerful modality of intraperitoneal micrometastasis and macroscopic PM eradication, and thereby PM down-staging.

\section{The role of cytoreductive surgery in the management of primary tumors, regional lymph node metastasis, and peritoneal metastasis}

Survival was significantly worse NIPS alone than after NIPS+radical gastrectomy [21,32]. Ishigami, et al. reported that 1- and 5-year survival rates were $56 \%$ and $0 \%$ after NIPS alone, and $73 \%$ and $16 \%$ after NIPS+gastrectomy [21]. Furthermore, the 5-year survival rate in patients who received CCR-0 resection after NIPS was 25\%, and 4 patients had no recurrence 5 years after gastrectomy. 17 Accordingly, gastrectomy plus D2 dissection improves long-term survival if macroscopic PMs completely disappear after NIPS.

The rate of postoperative Grade 3 or 4 morbidities of IPC+gastrectomy was $0-25 \%$, but the rate of postoperative mortality was $0 \%[21,33]$. Accordingly, gastrectomy+D2 dissection after NIPS can be performed safely with acceptable morbidities.

In contrast, 5-year survival rates after NIPS combined with incomplete cytoreduction (CCR-1) by radical gastrectomy without resection of PM were only low of $0-2 \%[21,32,34]$, and all patients died of the disease (Table 3). Distant PM can be completely removed by peritonectomy procedures [35] but not by ordinary surgical techniques [21]. Table 4 shows the outcomes of patients with PM treated with radical gastrectomy+peritonectomy+HIPEC with or without NIPS. Five-year survival rates ranged from $6 \%$ to $13 \%[9,34,36,37]$. Additionally, 18 of 284 patients were disease free 5 years after this treatment $[9,34,36,37]$.

CCR-0 resection is the most powerful prognostic factor, and the 5-year survival rate after CCR-0 resection using peritonectomy ranged from $6 \%$ to $15 \%$ [36-38]. Accordingly, after radical gastrectomy and resection of PM by peritonectomy techniques, CCR- 0 resection ca be performed for wide spread PM to increase long-term survival rates and even bringing about cure. However, the postoperative morbidities and mortalities were higher after peritonectomy+HIPEC than after gastrectomy+NIPS (Tables 3 and 4) [35,39]. Because of the high morbidity and mortality rates (0-6.5\%, mean:4.3\%), strict patients selection is vital [9].

\section{Cut-off pueritoneal cancer index (PCI) values [30]}

As mentioned above, CCR-0 has been credited with increasing life expectancy. However, postoperative mortality after gastrectomy+peritonectomy is still high $[34,36,37]$, The smaller the area of sector and organ resection, the lower is postoperative morbidity and mortality. Cut-off PCI values suggesting favorable long-term survival after CRS have been reported $[35,36,40]$. Yonemura $Y$, et al. proposed cut-off of $\leq 6$, corresponding to a low postoperative morbidity $(2.0 \%)$ and a favorable 5-year survival rate (18\%) [10].

Coccolini F, et al. performed a systematic review with meta-analysis of 1072 GC patients with PM. [41]. CCR-0 vs. CCR-1 achieved favorable 1- and 5-year survival rate (Risk Ratio: 2.41 and 7.96), respectively. They concluded that PCI cut-off value for favorable survival after CCR0 resection was $\leq 12$.

Yonemura $\mathrm{Y}$, et al. studied the risk factors for PM recurrence after CCR-0 from 193 GC patients [10]. Median overall survival was 21.6 months, and 5 -year survival rate was $18 \%$. Five years after CRS, 11 patients were disease free. Multivariate analysis identified small bowel peritoneal cancer index (SB-PCI) of $\leq 2$ as an independent favorable prognosticator. Patients with $\mathrm{PCI} \leq 12$ and $\mathrm{SB}-\mathrm{PCI} \leq 2$ were the best candidate for CRS $[10,41]$.

\section{Effects and side effects of hyperthermic intraperitoneal chemoperfusion (HIPEC)}

Hyperthermia acts synergistic with some kinds of anti-cancer drugs [31]. Additionally, hyperthermia enhances subperitoneal tissue penetration by drugs. HIPEC increased the depth of CDDP and carboplatinum penetration up to $3 \mathrm{~mm}$ from the peritoneal surface [22], and $40 \mathrm{~min}$. of HIPEC increased the depth of DTX penetration $1.46 \mathrm{~mm}[36,30,42]$.

Accordingly, HIPEC is considered to be an effective for PM treatment.

In 2017, Yonemura Y, et al. first reported the direct effect of HIPEC on PM from gastric cancer in 50 patients who underwent one cycle of neoadjuvant laparoscopic HIPEC and a $2^{\text {nd }}$ exploratory laparoscopy one month later to evaluate the effect of HIPEC [38]. Ascites completely disappeared or decreased in volume in 22 of 34 (64.7\%) patients and positive peritoneal cytology changed to negative cytology in 14 of $20(70 \%)$ patients at the $2^{\text {nd }}$ laparoscopy. The response was complete in $6(12 \%)$ patients, and peritoneal cancer indices were significantly reduced from $14.2 \pm 10.7$ at the $1^{\text {st }}$ LHIPEC to $11.8 \pm 11.0$ at the 2nd laparoscopy $(\mathrm{p}<0.05) .39$ Furthermore, lesion size scores [43] in the sector of the small bowel mesentery at the $1^{\text {st }}$ and $2^{\text {nd }}$ laparoscopy were $6.56 \pm 2.92$ and $5.25 \pm 3.78(\mathrm{P}=0.016)$. There was no intraoperative or postoperative complication and no mortality after LHIPEC [38]. Accordingly, diagnostic and therapeutic laparoscopy can be performed safely in patients with PM from GC. LHIPEC can be used as neoadjuvant treatment to reduce the tumor burden and achieve adequate control the disease. However, after one cycle of LHIPEC, the mean PCI reduction was only 2.4. Accordingly, only one cycle of LHIPEC is insufficiently to reduce the PCI score below the cut-off level.

Furthermore, in a study of NLHIPEC combined with 3 cycles of NIPS in 52 patients, NLHIPEC was followed by a series of $3 \times 3$-week cycles of NIPS and then by laparotomy for cytoreductive surgery and assessment of change in PCI [38]. Cytology was positive in 31 (59.6\%) patients at the NLHIPEC and changed from positive to negative in 22 (71\%) of the 31 patients at laparotomy [38]. PCI $\leq 12$ in $16(30.2 \%)$ of 52 patients at NLHIPEC, and 31 (58\%) of 52 patients after NLHIPEC+ 3 courses of NIPS $(\mathrm{P}=0.029)$. Additionally, PM disappeared in $6(11.5 \%)$ patients. PCI at laparotomy decreased in $29(55.8 \%)$ patients and increased 6 (11.6\%) patients [38].

PCI was significantly lower at laparotomy $(9.9 \pm 11.3)$ than that at NLHIPEC $(14.8 \pm 11.4)$. After NLHIPEC+NIPS, complete cytoreduction was achieved in $30(57.6 \%)$ patients [38]. Accordingly, 


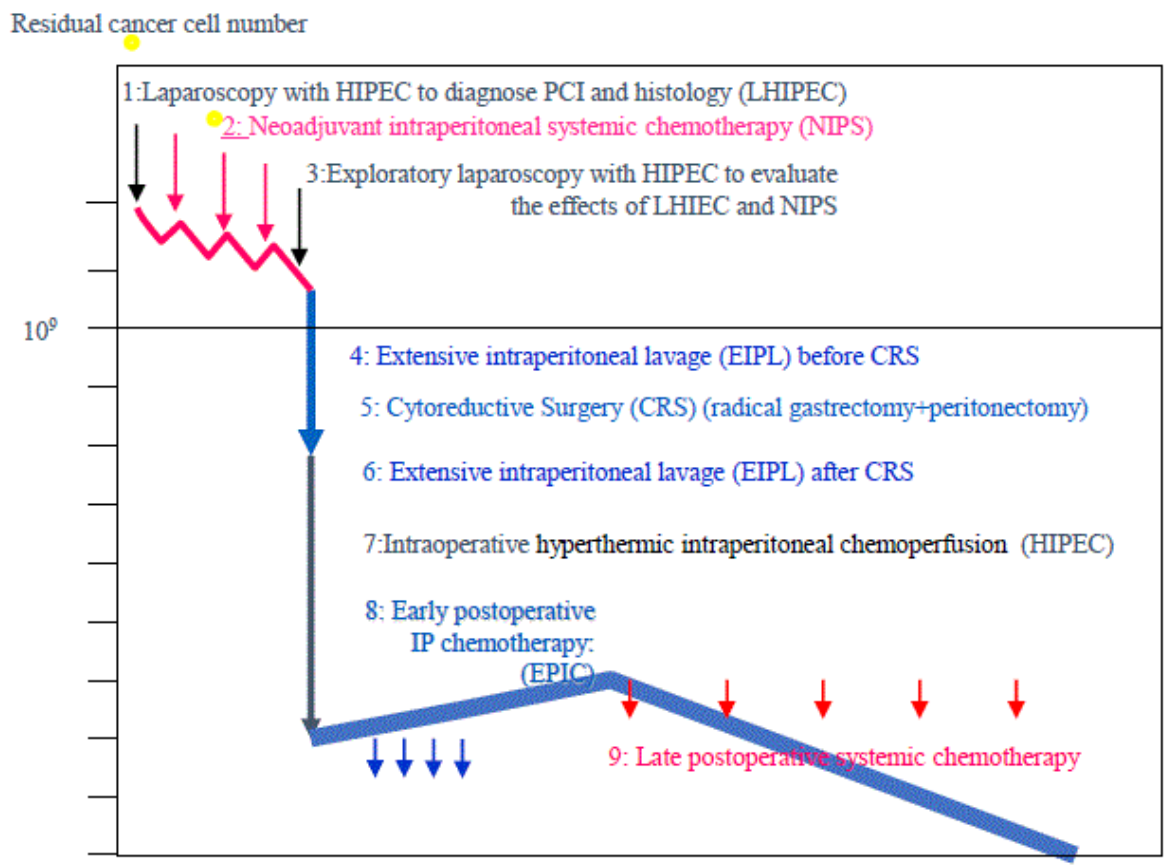

Figure 1. Treatment options for peritoneal metastases from gastric cancer

NLHIPEC combined with 3 cycles of NIPS can effectively reduce PCI levels before CRS.

This strategy impacts not only pretreatment PCI, but the enhancement of the effect of NLHIPEC by NIPS. During NLHIPEC and NIPS, additionally, patients can be selected for CRS by evaluating IP port cytology, serum tumor marker levels, and computed tomography and/or positron emission tomography studies.

In a randomized control trial of CRS+intraoperative HIPEC without neoadjuvant chemotherapy vs. CRS alone, Yang XJ, et al. concluded that intraoperative HIPEC confers a significant survival benefit [40].

At the present time, comprehensive treatment combined with neoadjuvant chemotherapy, cytoreductive surgery and intraoperative HIPEC can be performed with intent to cure PM from GC.

\section{Conclusion}

Among the nine comprehensive treatment options (Figure 1), CRS after NIPS play important roles in achieving successful outcomes in GC patients with PM. NIPS reduce PCI and SB-PCI, thereby increasing CCR-0.

Candidates for CRS should be selected during NIPS by cytological examination, serum tumor marker levels, and diagnostic imaging studies. After NIPS, radical gastrectomy+peritonectomy is recommended. The final goal is CCR-0 resection and the residual micrometastasis is treated with intraoperative HIPEC, EPIC, and late postoperative chemotherapy.

\section{References}

1. Chau I, Norman Ar, Cunningham D, Waters JS, Oates J, et al. (2004) Multivariate prognostic factor analysis in locally advanced and metastatic esophago-gastric cancerpooled analysis from three multicenter, randomized controlled trials using individual patient data. J Clin Oncol 22: 2395-403. [Crossref]

2. Koizumi W, Narahara H, Hata T, Takagane A, Akiya T, et al. (2008) S-1 plus cisplatin versus S-1 alone for first-line treatment of advanced gastric cancer (SPIRITS trial): a phase III trial. Lanct Oncol 9: 215-221. [Crossref]
3. Bang YJ, Van Cutsem E, Feyereislova A, Chung HC, Shen L, et al. (2010) Trastuzumab in combination with chemotherapy versus chemotherapy alone for treatment of HER2positive advanced gastric or gastro-oesophageal junction cancer (ToGA): a phase 3 , open-label, randomised controlled trial. Lancet 376: 687-697. [Crossref]

4. Nishina T, Boku N, Gotoh M, Shimada Y, Hamamoto Y, et al. (2016) Randomized phase II study of second line chemotherapy with the best available 5-fluorouracil regimen versus weekly administration of paclitaxel in far advanced gastric cancer with severe peritoneal metastases refractory to 5-flurouracil-containing regimens (JCOG407). Gastric Cancer 19: 902-910. [Crossref]

5. Imamoto H, Oba K, Sakamoto J, Iishi H, Narahara H, et al. (2011) Assessing benefit response in the treatment of gastric malignant ascites with non-measurable lesions: a multicenter phase Ii trial of paclitaxel for malignant ascites secondary to advanced/ recurrent gastric cancer. Gastric Cancer 14: 81-90. [Crossref]

6. Hong SH, Shin YR, Roh SY, Jeon EK, Song KY, et al. (2013) Treatment outcomes of systemic chemotherapy for peritoneal carcinomatosis arising from gastric cancer with no measurable disease: retrospective analysis from a single center. Gastric Cancer 16: 290-300. [Crossref]

7. Wilke H, Muro K, Van Custem E, Oh SC, Bodoky G, et al. (2014) Ramucirumab plus paclitaxel versus placebo plus paclitaxel in patients with previously treated advanced gastric cancer or gastro-esophageal junction adenocarcinoma (RAINBOW): a doubleblind, randomized phase 3 trial. Lancet Oncol 15: 1224-1235. [Crossref]

8. Yonemura Y, Bandou E, Sawa T, Yoshimitsu Y, Endou Y, et al. (2006) Neoadjuvant treatment of gastric cancer with peritoneal dissemination. Eur J Surg Oncol 32: 661665. [Crossref]

9. Glehen O, Schreiber V, Cotte E, Sayag-Beaujard AC, Osinsky D, et al. (2004) Cytoreductive surgery and intraperitoneal chemohyperthermia for peritoneal carcinomatosis arising from gastric cancer. Arch Surg 139: 20-26. [Crossref]

10. Yonemura Y, Canbay E, Sako S, Ishibashi H, Hirano M, et al. (2016) Risk factors for recurrence after complete cytoreductive surgery and perioperative chemotherapy in peritoneal metastases from gastric cancer. J Integlr Oncol 5: 167.

11. Jacquet P, Sugarbaker PH (1996) Peritoneal-plasma barrier. Cancer Treat Res 82: 53 63. [Crossref]

12. Li F, Tiede B, Massagu J, Kang Y (2007) Beyond tumorigenesis: cancer stem cells in metastasis. Cell Res 17: 3-14. [Crossref]

13. Bando E, Yonemura Y, Takeshita Y, Taniguchi K, Yasui T, et al. (1999) Intraoperative lavage for cytological examination in 1297 patients with gastric carcinoma. Am J Surg 178: 256-262. [Crossref]

14. Japanese classification of gastric carcinoma (1998) Japanese Gastric Cancer Association. 2nd English Edition. Gastric Cancer 1: 10-24. 
15. Kodera Y, Ito S, Mochizuki Y, Kondo K, Koshikawa K, et al. (2009) A phase II study of radical surgery followed by postoperative chemotherapy with S-1 for gastric carcinoma with free cancer cells in the peritoneal cavity. Eur J Surg Oncol 35: 11581163. [Crossref]

16. Yonemura Y, Endou Y, Bando E (2006) The usefulness of oral TS-1 treatment for potentially curable gastric cancer patients with intraperitoneal free cancer cells. Cancer Therapy 4: 135-142.

17. Fujiwara Y, Takiguchi S, Nakajima K, Miyata H, Yamasaki M, et al. (2012) Intraperitoneal docetaxel combined with S-1 for advanced gastric cancer with peritoneal dissemination. $J$ Surg Oncol 105: 38-42. [Crossref]

18. Yonemura Y, Canbay E, Sako S, Ishibashi H, Hirano M, et al. (2014) Phase Il study of comprehensive treatment using perioperative chemotherapy combined with cytoreductive surgery for curatively resected gastric cancer patients with positive peritoneal wash cytology. Global J Gastroenterol Hepatol 2: 1-6.

19. Kuramoto M, Shimada S, Ikeshima S, Matsuo A, Yagi Y, et al. (2009) Extensive intraoperative peritoneal lavage as a standard prophylactic strategy for peritoneal recurrence in patients with gastric carcinoma. Ann Surg 250: 242-246.

20. Imano M, Imamoto H, Itoh T, Satou T, Peng YF, et al. (2011) Inpact of intraperitoneal chemotherapy after gastrectomy with positive cytological findings in peritoneal washings. Eur Surg Res 47: 254-259. [Crossref]

21. Ishigami H, Yamaguchi H, Yamashita H, Asakage M, Kitayama J, et al. (2017) Surgery after intraperitoneal and systemic chemotherapy for gastric cancer with peritoneal metastasis or positive peritoneal cytology. Gastric Cancer 20: S128-S134. [Crossref]

22. Los G, Mutsaers PHA, van der Vijgh WJ, Baldew GS, de Graaf PW, et al. (1989) Direct diffusion of cis-diamminedichloroplatinum (II) in intraoperitoneal rat tumors after intraperitoenal chemotherapy: A comparison with systemic chemotherapy. Cancer Res 49: 3380-3384. [Crossref]

23. Sugarbaker PH, Van der Speeten (2016) Surgical technology and pharmacology of hyperthermic perioperative chemotherapy. J Gastroenterol Oncol 7: 29-44.

24. Kamei T, Kitayama J, Yamaguchi H, Soma D, Emoto S, et al. (2011) Spatial distribution of intraperitoneally administered paclitaxel nanoparticles solubilized with poly (2-methacry-loxyethyl phosphorylcholine-co-n-butyl metacrylate) in peritoneal metastatic nodules. Cancer Sci 102: 200-205. [Crossref]

25. Yamaguchi H, Kitayama J, Ishigami H, Kazama S, Nozawa H, et al. (2015) Breakthrough therapy foe peritoneal carcinomatosis of gastric cancer: Intraperitoneal chemotherapy with taxans. World J Gastroenterol Oncol 7: 285-291.

26. Wang ZB, Li M, Li JC (2010) Recent advances in the research of lymphatic stomata. Anat Rec (Hoboken) 293: 754-761. [Crossref]

27. Kurita N, Shimada M, Iwata T, Nishioka M, Morimoto S, et al. (2011) Intraperitoneal infusion of paclitaxel with S-1 for peritoneal metastasis of advanced gastric cancer: phase 1 study. J Med Invest 58: 134-139.

28. Fushida S, Kinoshita J, Kaji M, Hirono Y, Goda F, et al. (2013) Phase I/II study of intraperitoneal; docetaxel plus S-1 for gastric cancer patients with peritoneal carcinomatosis. Cancer Chemother Pharmacol 71: 1265-1272. [Crossref]

29. Miyamoto K, Shimada T, Sawamoto K, et al. (2012) Disposition kinetics of taxans in peritoneal dissemination. Gastroenterol Res Pract 2012: 963403.
30. Yonemura Y $\square$ Endou Y, Bando E, Kuno K, Kawamura T, et al. (2004) Effect of intraperitoneal administration of docetaxel on peritoneal dissemination of gastric cancer. Cancer Let 16: 189-196. [Crossref]

31. de Bree E, Tsiftsis.DD (2007) Experimental and pharmacologic studies in intraperitoneal chemotherapy from laboratory bench to bedside. Advances in peritoneal surface oncology. S. Gonzalez-Moleno ed. Springer, pp: 53-73

32. Yonemura Y, Endou Y, Shinbo M, Sasaki T, Hirano M, et al. (2009) Safety and efficacy of bidirectional chemotherapy for treatment of patients with peritoneal dissemination from gastric cancer: Selection for cytoreductive surgery. J Surg Oncol 100: 311-316. [Crossref]

33. Fushida S, Kinoshita J, Yago Y, Funaki H, Kinami S, et al. (2008) Dual anti-cancer effects of weekly intraperitoneal docetaxel treatment of advanced gastric cancer patients with peritoneal carcinomatosis: A feasibility and pharmacokinetic study. Oncology Rep 19: 1305-1310. [Crossref]

34. Yonemura Y, Elnemr A, Endou Y, et al. (2010) Multidisciplinary $\square$ therapy $\square$ for $\square$ tre atment $\square$ of $\square$ patients $\square$ with $\square$ peritoneal $\square$ carcinomatosis from gastric cancer. World $J$ Gastrointest Oncol 15: 85-97. [Crossref]

35. Yonemura Y, Elnemr A, Endou Y, Ishibashi H, Mizumoto A, et al. (2012) Surgical Results of Patients with Peritoneal Carcinomatosis Treated with Cytoreductive Surgery Using a New Technique Named Aqua Dissection. Gastroenterol Res Pract 2012 521487. [Crossref]

36. Glehen O, Gilly FN, Arvieux C, Cotte E, Boutitie F, et al. (2010) Peritonea carcinomatosis from gastric cancer: a multi-institutional study of 159 patients treated by cytoreductive surgery combined with perioperative intraperitoneal chemothermia Ann Surg Oncol 9: 2370-2377. [Crossref]

37. Hall JJ, Loggie BW, Shen P, e Beamer S, Douglas Case L, et al. (2004) Cytoreductive surgery with intraperitoneal hyperthermic chemotherapy for advanced gastric cancer. $J$ Gastroenterol Surg 8: 454-463. [Crossref]

38. Yonemura Y, Ishibashi H, Hirano M, Mizumoto A, Takeshita K, et al. (2017) Effects of Neoadjuvant Laparoscopic Intraperitoneal chemotherapy and neoadjuvant intraperitoneal/systemic chemotherapy on peritoneal metastasis from gastric cancer. Ann Surg Oncol 24: 478-485. [Crossref]

39. Imano M, Imamoto H, Itoh T, Satou T, Peng YF, et al. (2012) Safety of intraperitoneal administration of paclitaxel after gastrectomy with en-block D2 lymph node dissection. J Surg Oncol 105: 43-47. [Crossref]

40. Yang XJ, Huang CQ, Suo T, Mei LJ, Yang GL, et al. (2011) Cytoreductive surgery and hyperthermic intraperitoneal chemotherapy improves survival of patients with peritoneal carcinomatosis from gastric cancer: Final results of a phase III randomized clinical trial. Ann Surg Oncol 18: 1575-1581. [Crossref]

41. Coccolini F, Catena F, Glehen O, Yonemura Y, Sugarbaker PH, et al. (2015) Complete versus incomplete cytoreduction in peritoneal carcinosis from gastric cancer, with consideration to PCI cut-off. Systematic review and meta-analysis. Eur J Surg Oncol 41: 911-919. [Crossref]

42. Yonemura Y, Canbay E, Sako S, Ishibashi H, Hirano M, et al. (2014) Pharmacokinetics of docetaxel during hyperthermic intraperitoneal chemotherapy for peritoneal metastasis. Gan To Kagaku Ryoho 41: 2496-2499. [Crossref]

43. Portilla AG, Shigeki K, Dario B, Marcello D (2008) The intraoperative staging systems in the management of peritoneal surface malignancy. J Surg Oncol 98: 228-231. [Crossref]

Copyright: (C2018 Taniguchi K. This is an open-access article distributed under the terms of the Creative Commons Attribution License, which permits unrestricted use, distribution, and reproduction in any medium, provided the original author and source are credited. 